\title{
Cardiovascular Responses to Postural Changes in the Neonate
}

\author{
C. G. PICTON-WARLOW ${ }^{\star}+$ and FLORENCE E. MAYER \\ From the Unit for Research in the Newborn of The Children's Medical Research Foundation, \\ Royal Alexandra Hospital for Children, Camperdown, New South Wales, Australia
}

Picton-Warlow, C. G., and Mayer, F. E. (1970). Archives of Disease in Childhood, 45, 354. Cardiovascular responses to postural changes in the neonate. The responses of pulse rate, systolic blood pressure, forearm blood flow, and respiratory rate to passive tilting have been studied in mature infants.

Cardiovascular responses to postural change were comparable to those of the adult and were present from birth. These findings support the view that well-developed circulatory reflexes are present from birth.

Respiratory rate tended to slow on tilting, which is different from the adult response.

In adult man passive head-up tilting has been shown to evoke a vasoconstrictor response, with a diminution in forearm blood flow (Brigden, Howarth, and Sharpey-Schafer, 1950) and an increase in heart rate. A fall in right atrial pressure of some $7 \mathrm{~mm}$. $\mathrm{Hg}$ occurs with a subsequent fall in cardiac output and, initially, a small fall in mean arterial blood pressure.

In the newborn infant, passive head-up tilting has been shown to result in an increase in heart rate (Young and Holland, 1958). A small rise in systolic blood pressure, measured clinically, has been described in babies who were resting but awake at the time of investigation (Young and Holland, 1958; Hakulinen, Hirvonen, and Peltonen, 1962). Direct measurements of aortic blood pressure have shown an initial increase followed by a fall in both systolic and diastolic pressure (Oh et al., 1966; Moss, Duffie, and Emmanouilides, 1963).

Babies in a wakeful but resting state are liable to be aroused by tilting, and such arousal would probably interfere with observation of vasomotor responses (Hakulinen et al., 1962). The present

Received 11 September 1969.

$\star$ Supported by Grant-in-Aid G 51, National Heart Foundation of Australia.

tWe record with regret Dr. Picton-Warlow's death in an air accident on 10 September 1969 , at the age of 33 . He was returning to Perth to take up the post of Senior Lecturer in the Department of Child Health, University of Western Australia, after working for two years in the Neonatal Research Unit, Hammersmith Hospital. His loss is deeply felt among his many friends in paediatrics, especially in Australia and Britain.

Editors. investigation was undertaken in soundly sleeping $\vec{\varphi}$ infants to eliminate this influence and to attempt 0 to show the response of pulse, systolic blood pressure and forearm blood flow to postural change alone. Limb blood flow in the newborn has been studied by others (Celander, 1960; Riley, 1954), ֶ but its response to postural change has not pre- $\mathbb{\Phi}$ viously been described.

\section{Methods}

Twenty mature infants were examined serially between the ages of 4 hours and 12 days. Examinations were made half an hour after feeding. Care was taken 응 to ensure that all subjects were asleep and motionless; $;$ sedation was not used. The baby was placed in a 3 . moulded foam rubber pad on a hinged table-top and 8 supported by a sling under the axillae, leaving the 3 thorax and abdomen unimpeded. This arrangement enabled smooth elevation from the supine position to $\frac{}{5}$ $70-80^{\circ}$ without disturbing the subject or constricting $\frac{D}{2}$ the arm. Recordings were performed for 3- to 4minute periods in each position, and the procedure was $\mathrm{N}$ repeated 3 to 5 times. The result was discarded if the baby woke or moved on tilting.

Pulse rate was recorded ${ }^{\star}$ continuously as a cardio- N tachometer tracing. Respiratory movement was re- $O$ corded as a pneumograph from a low frequency microphone strapped to the abdomen.

Systolic blood pressure was measured indirectly. A $3 \mathrm{~cm}$. wide cuff encircling the upper arm was con- ? nected to a Statham P23DB strain gauge to give a $T$ continuous record of the cuff pressure. A small carbon

^Electronics for Medicine D.R. 8 Research Recorder. 
microphone placed at the wrist simultaneously recorded the radial pulse. The systolic blood pressure was taken as the point on the cuff tracing at which the first impulse was recorded at the wrist during slow deflation of the cuff after it had been rapidly inflated. The arm was placed at right angles so that it would be at heart level when the baby was erect. Measurements of systolic blood pressure were made 3 to 6 times in each position.

Forearm blood flow was measured by venous occlusion plethysmography. A $3 \mathrm{~cm}$. wide cuff around the upper arm was inflated to 20 to $25 \mathrm{~mm}$. $\mathrm{Hg}$. The increase in the size of the arm due to arterial inflow after occlusion of the vein was measured as the rise in pressure in a second air-filled plastic cuff closely applied to the mid-forearm and held in place by a stiff plastic binder which prevented outward expansion of the cuff. As with other methods of plethysmography an initial deflection due to tissue displacement was often seen, followed by a steady increase in pressure for 5-10 seconds as the arm filled with blood (Fig. 1). The lower cuff was calibrated by injection of $0.1 \mathrm{ml}$. air from a tuberculin syringe, and the height above the baseline was measured when pressure had stabilized. The length of arm under the cuff and its circumference on either side were measured and hence the volume of limb under the cuff was calculated. Blood flow was expressed as $\mathrm{ml}$. blood $/ 100 \mathrm{ml}$. tissue per minute.

A direct comparison between this method of forearm plethysmography and the conventional method using a water-filled forearm plethysmograph and volume recorder was undertaken on adult subjects. With the subject recumbent and at rest there was good agreement between the air-filled cuff on one arm and the water plethysmograph on the other. Blood flows of 1-5 $\mathrm{ml} . / 100 \mathrm{ml}$. per min. were observed. Increase in blood flow up to $8 \mathrm{ml} . / 100 \mathrm{ml}$. per min. by causing the subject to perform mental arithmetic and thus increase muscle blood flow was also measured accurately by the cuff method. When skin blood flow was increased, reflexly, by heating the subjects legs in hot water, blood flows of up to $10 \mathrm{ml} . / 100 \mathrm{ml}$. per min. were induced. In this case, at the high rate of flow, measurements with the cuff plethysmograph tended to be lower than those with the water-filled plethysmograph. Thus at the higher rates of flow the cuff appeared to interfere with skin blood flow. This may have been due to partial compression of the blood vessels in the skin by the rise in cuff pressure. The adult experiments were thought to validate the method for the purposes of our observations, since the changes we were studying in infants were believed to be mainly in muscle blood flow (Brigden $e t$ al., 1950).

Change in forearm blood flow with tilting was measured in five babies at room temperature of $22-27^{\circ} \mathrm{C}$. Three to six measurements were made alternately in the supine and erect positions and the results were averaged. The tilt was repeated three to five times at each examination. Examinations were made during the first 36 hours of life and repeated twice during the next 7 days.

Right atrial pressure was measured in the supine and erect positions in two anencephalic infants. A 5 French plastic feeding tube was passed into the right atrium via the umbilical vein, and pressure was recorded with a Statham P23DB strain gauge placed at midaxillary level for each position of the infant.

\section{Results}

From the earliest age a small rise in pulse rate occurred on tilting to the head-up position (Fig. 2). Cardiac acceleration was immediate and was sus-
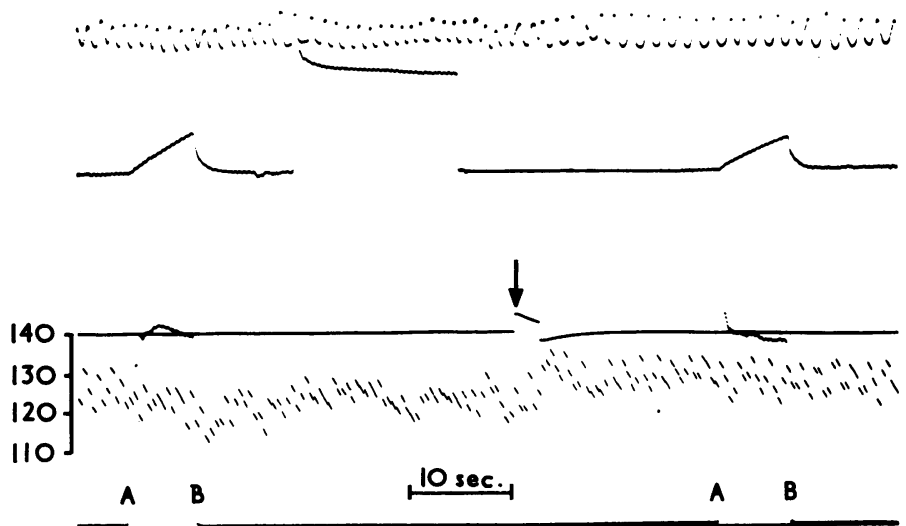

FIG. 1.-Record of respirations, forearm blood flow measurement, and cardiotachometer. The upper record is of respiratory movement. The lower interrupted record is of the cardiotachometer, and the figures in the left indicate the heart rate in beats per minute. Infant initially supine and then tilted to $80^{\circ}$ at the arrow. The upper arm cuff was inflated to $25 \mathrm{~mm} . \mathrm{Hg}$ between $A$ and $B$ and the steady increase in pressure in the forearm plethysmograph cuff due to arterial inflow in the arm can be seen in the second tracing from the top. Following the first flow measurement, the pressure increase due to injecting the calibrating volume of $0.1 \mathrm{ml}$. can also be seen. 


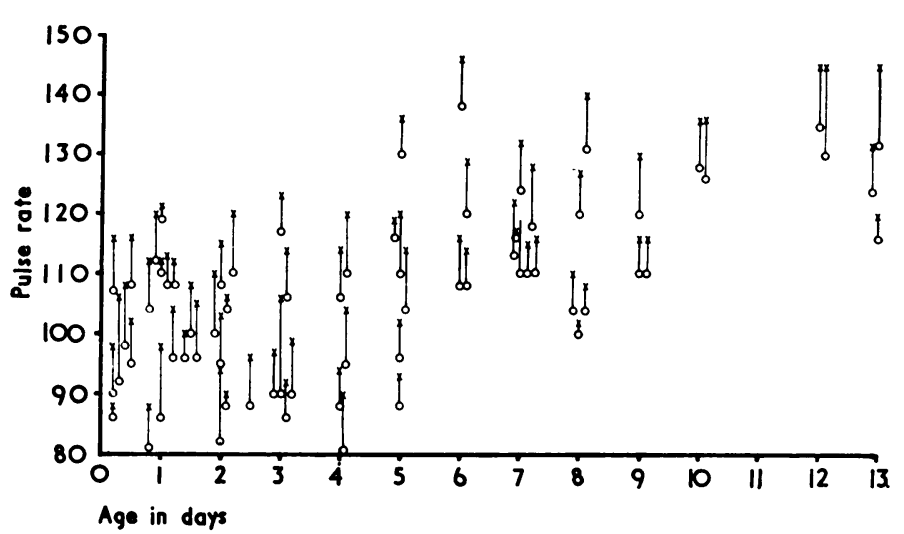

FIG. 2.-Change in pulse rate on tilting head-up between $70^{\circ}-80^{\circ}$. $\quad 0=$ average pulse rate for $2-3$ minutes before $\stackrel{ \pm}{\overrightarrow{5}}$ tilting. $\times=$ average pulse rate for 2-3 minutes after tilting. 70 observations performed serially on 15 babies, of average rise $7 \cdot 7$ beats/min. (SD $3 \cdot 3$ ).

tained while in the upright position, with a rapid return to the control level on resuming the supine position (Fig. 3). The previously reported rise in resting pulse with advancing age (Young and Holland, 1958) was also seen.

Respiratory rate slowed with tilting, though not invariably. The greater the decline in respiratory rate on tilting, the less marked was cardiac acceleration. The regression line comparing percentage pulse rate change and percentage respiratory rate change shows a $7 \cdot 7 \%$ rise in pulse rate from the rate when supine for no change in respiratory rate (Fig. 4).

Systolic blood pressure fell $3-8 \mathrm{~mm}$. $\mathrm{Hg}$ on tilting (Fig. 5). The fall occurred soon after tilting $\vec{c}$ (Fig. 3) and the blood pressure was well maintained at its new level. There was a tendency for systolic ${ }^{\oplus}$ blood pressure to rise with age (Fig. 5), as reported $\vec{\theta}$ by others (Young and Holland, 1958; Holland and $O$ Young, 1956; Goodman, Cumming, and Raber, 1962).

Right atrial pressure, in the two infants examined, was 2.1 and $1.9 \mathrm{~mm}$. $\mathrm{Hg}$ in the supine position. These pressures fell on tilting to 0.9 and $1.2 \mathrm{~mm}$. Hg.

Forearm blood flow always decreased with tilting (Fig. 6). The mean fall was $34 \%$ of the supine level (SD 8.1\%).

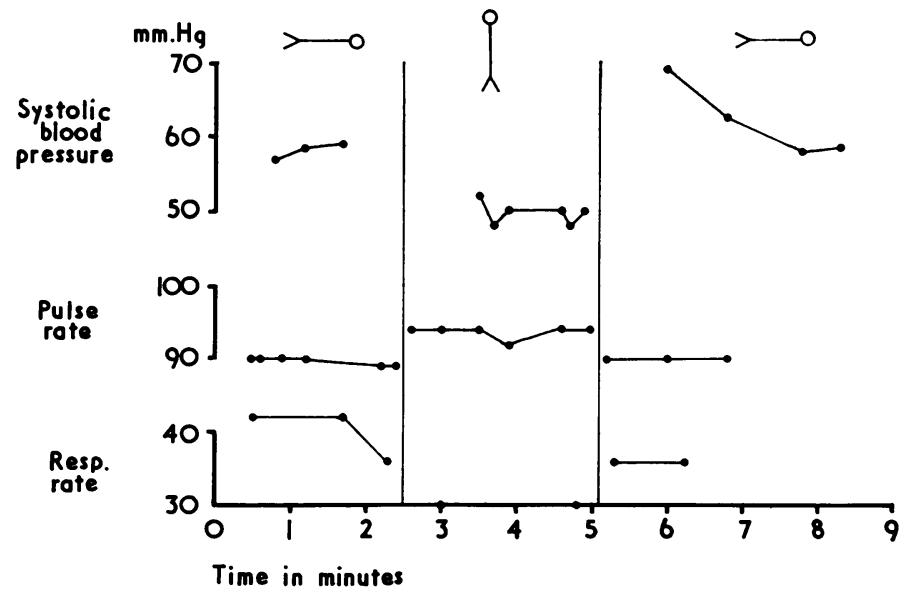

FIG. 3.-Diagram to show changes in systolic blood pressure, pulse rate, and respiratory rate on tilting in one baby aged 4 days. Each point for pulse and respiration is the average for 20 seconds. 


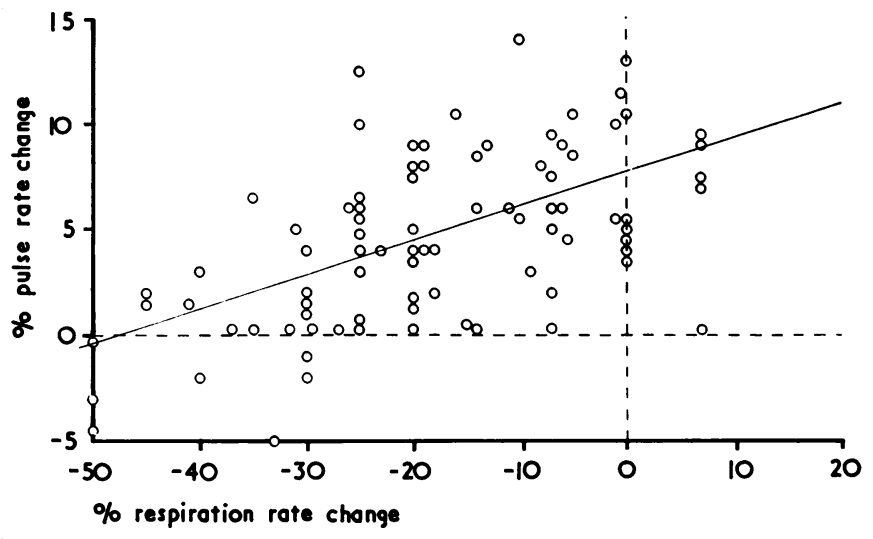

FIG. 4.-Relation between percentage pulse rate change and percentage respiratory rate change on tilting. 93 observations in 11 babies. The regression equation is: $y=7 \cdot 7+0 \cdot 16 x . S D 3 \cdot 3$. Correlation coefficient $=0 \cdot 7$.

Celander (1960) found no change in blood flow with age after 12 hours. Our observations suggested that it increased, but this was at room temperature, whereas his studies were done at $32{ }^{\circ} \mathrm{C}$. Consequently, seven more babies were examined in an environmental temperature of $32-33^{\circ} \mathrm{C}$. These infants were supine in an incubator, and measurements were made at the age of 12-24 hours and repeated at the age of 10 days. They were not tilted. Forearm flow was $3 \cdot 7$ $\mathrm{ml}$./100 ml. per min. (SD 1.3, n 14) and no dif- ference was found between the ages of 12 hours and 10 days.

\section{Discussion}

A rise in pulse rate of $15-40$ beats per minute on tilting from the supine to the upright position was found in the newborn period by Young and Holland (1958). In the present investigation this response was considerably smaller, and the supine pulse rates were on the whole 10 to 20 beats per minute lower than reported by those authors. Even a small

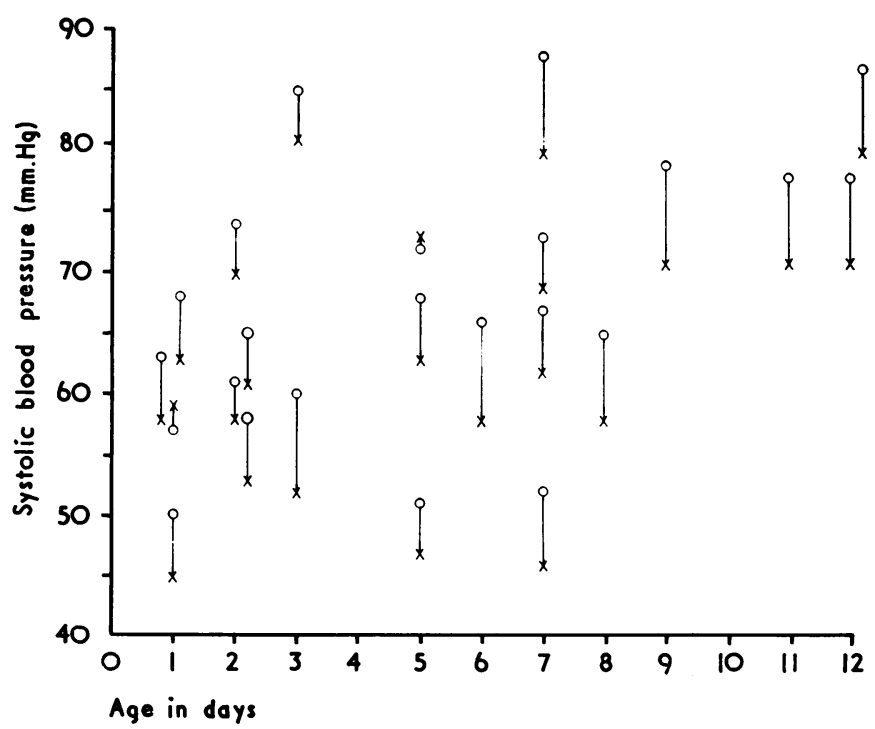

FIG. 5.-Fall in systolic blood pressure on tilting. 5 babies examined serially. $\quad \circ=$ average of 3-5 readings in supine position. $\quad \times=$ average of $3-5$ readings after tilting. 


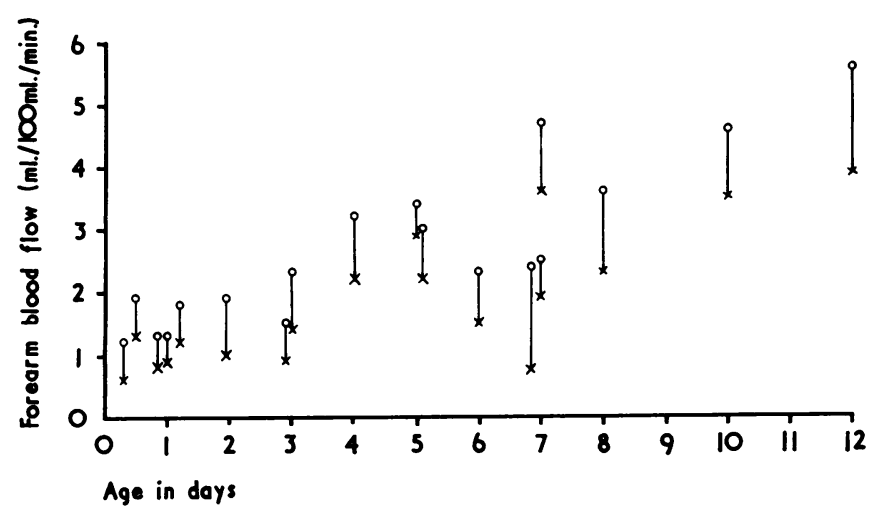

FIG. 6.-Fall in forearm blood flow on tilting. 5 babies observed serially. $O=$ average of 3-5 measurements of $\mathrm{N}$ forearm blood flow in the supine position. $\quad \times=$ average of 3-5 measurements of forearm blood flow in erect position.

amount of somatic movement is associated with prompt and considerable cardio-acceleration (Lipton, Steinschneider, and Richmond, 1961). The differences in pulse rate response in the two series may be explained by motor activity on tilting in the former series which did not occur in the present investigation in which the babies were deeply asleep.

The relation found between respiratory slowing and heart rate change may be explained by alterations in the efficiency of the 'abdomino-thoracic pump' (Rushmer, 1961). Slower breaths in the upright position may be associated with larger intrathoracic pressure swings helping to augment venous return, thus masking or reducing cardiac acceleration on tilting.

In the adult there is either no change or a slight increase in respiratory rate on tilting (Bjurstedt et al., 1962). Other reports of cardiovascular changes with posture in the newborn have had nothing to say on respiratory changes. Since respiratory responses were not the immediate concern of this study, the slowing of respiratory rate with tilting was not investigated further.

The reduction in forearm blood flow on tilting was comparable to the adult in whom a fall of $40 \%$ occurs (Brigden et al., 1950). Systolic blood pressure fell a little, whereas most resting adults, despite a fall in cardiac output, experienced no change in blood pressure when tilted (Brigden et al., 1950). The difference may have been in some way related to the fact that the babies were deeply asleep. Their vasoconstrictor response was none the less as active as in the adult. Hence, vasomotor inactivity or 'immaturity' is unlikely to be the explanation for the slightly lower systolic blood pressure in the upright position. Perhaps the demands of cerebral blood flow in the infant are so $c$ great that pronounced vasoconstriction elsewhere does not compensate for the fall in cardiac output.

The responses of the newborn circulatory system $\vec{\varphi}$ to tilting were the same in the first three days as. later. They were comparable to the adult from the earliest age. These observations provide good evidence of a well-developed control of peripheral circulation from birth.

We thank Professor R. F. Whelan, Department of Human Physiology and Pharmacology, University of Adelaide, for facilities provided for checking the method of measuring forearm blood flow, and also Dr. E. D. Burnard for help and direction in this work.

\section{REFBRENCES}

Bjurstedt, H., Hesser, C. M., Liljestrand, G., and Matell, G. (1962) Effects of posture on alveolar-arterial $\mathrm{CO}_{2}$ and $\mathrm{O}_{2}$ differences and on alveolar dead space in man. Acta Physiologica Scandinavica, 54, 65.

Brigden, W., Howarth, S., and Sharpey-Schafer, E. P. (1950) Postural changes in the peripheral blood flow of normal subjects with observations on vasovagal fainting reactions as a result of tilting, the lordotic posture, pregnancy and spinal anaesthesia. Clinical Science, 9, 79 .

Celander, O. (1960). Blood flow in the foot and calf of the newborn. Acta Paediatrica, 49, 488.

Goodman, H. G., Cumming, G. R., and Raber, M. B. (1962). Photocell oscillometer for measuring systolic pressure in newborn. American fournal of Diseases of Children, 103, 152.

Hakulinen, A., Hirvonen, L., and Peltonen, T. (1962). Response of blood pressure in sucking and tilting in the newborn. Annales Paediatrice Fenniae, 8, 56.

Holland, W. W., and Young, I. M. (1956). Neonatal blood pressure in relation to maturity, mode of delivery and condition at birth. British Medical fournal, 2, 1331.

Lipton, E. L., Steinschneider, A., and Richmond, J. B. (1961). Autonomic function in the neonate. IV. Individual differences in cardiac reactivity. Psychosomatic Medicine, 23, 472. 
Moss, A. J., Duffie, E. R., Jr., and Emmanouilides, G. (1963). Blood pressure and vasomotor reflexes in the newborn infant. Pediatrics, 32, 175.

Oh, W., Arcilla, R. A., Oh, M. A., and Lind, J. (1966). Renal and cardiovascular effects of body tilting in the newborn infant. Biologia Neonatorum, 10, 76.

Riley, I. D. (1954). Hand and forearm blood flow in full-term and premature infant. Clinical Science, 13, 317.

Rushmer, R. F. (1961). Cardiovascular Dynamics, 2nd ed., p. 179. Saunders, Philadelphia.
Young, I. M., and Holland, W. W. (1958). Some physiological responses of neonatal arterial blood pressure and pulse rate. British Medical fournal, 2, 276.

Correspondence to Dr. F. E. Mayer, Growth and Development Branch, National Institute of Child Health and Human Development, Bethesda, Maryland 20014, U.S.A. 